\title{
EthoSeq: A tool for phylogenetic analysis and data mining in behavioral sequences
}

\author{
HILTON F. JAPYASSÚ \\ Instituto Butantan, São Paulo, Brazil \\ CARLOS C. ALBERTS \\ Universidade Estadual Paulista, São Paulo, Brazil \\ and \\ PATRÍCIA IZAR and TAKECHI SATO \\ University of São Paulo, São Paulo, Brazil
}

\begin{abstract}
This article introduces the software program called EthoSeq, which is designed to extract probabilistic behavioral sequences (tree-generated sequences, or TGSs) from observational data and to prepare a TGS-species matrix for phylogenetic analysis. The program uses Graph Theory algorithms to automatically detect behavioral patterns within the observational sessions. It includes filtering tools to adjust the search procedure to user-specified statistical needs. Preliminary analyses of data sets, such as grooming sequences in birds and foraging tactics in spiders, uncover a large number of TGSs which together yield single phylogenetic trees. An example of the use of the program is our analysis of felid grooming sequences, in which we have obtained 1,386 felid grooming TGSs for seven species, resulting in a single phylogeny. These results show that behavior is definitely useful in phylogenetic analysis. EthoSeq simplifies and automates such analyses, uncovers much of the hidden patterns of long behavioral sequences, and prepares this data for further analysis with standard phylogenetic programs. We hope it will encourage many empirical studies on the evolution of behavior.
\end{abstract}

Considerable efforts have been made (Brooks \& McLennan, 1991; Odling-Smee, Laland, \& Feldman, 2003) to unify two radically distinct branches of biological research: ecology, focusing on adaptation to local conditions; and phylogeny, focusing on historical constraints on adaptation. This debate is important in the behavioral domain, where the liability of behavioral expression has been used as an argument against the employment of behavioral characters in the reconstruction of phylogenetic patterns (see, e.g., Atz, 1970). Notwithstanding this criticism, empirical studies have indicated that stereotyped behavioral characteristics are as useful in reconstructing phylogenetic relationships as morphological and molecular traits (see De Queiroz \& Wimberger, 1993; McLennan, Brooks, \& McPhail, 1988; Paterson, Wallis, \& Gray, 1995; Prum, 1994; Slikas, 1998), and some authors suggest applying general methods to evolutionary studies of animal behavior (see Martins, 1996).

To solve this problem, more comparative data on behavior are needed, especially on the plastic aspects of

H.F.J. was supported by a grant from FAPESP, P.I. was supported by a grant from CAPES, and T.S. was supported by a grant from Conselho Nacional de Pesquisa. The authors thank Vincenç Quera, Andreas Altorfer, and an anonymous reviewer for their detailed critical comments on the manuscript. Correspondence concerning this article should be addressed to H. F. Japyassú, Laboratório de Artrópodes/Instituto Butantan, Av. Vital Brazil 1500, São Paulo, SP/05503-900, Brazil (e-mail: japyassu@butantan.gov.br). performance - that is, the aspects responsive to environmental fluctuations, which are still underexplored in evolutionary studies. Long behavioral sequences, consisting of an accumulation of small, easily identifiable acts, are interesting in this regard because, unlike stereotyped details of performance, they recover much of their inherent behavioral plasticity, and thus render plasticity tractable in a phylogenetic context (see Japyassú \& Viera, 2002).

There are clear statistical solutions to the analysis of behavioral sequences (Bakeman \& Gottman, 1997; Bakeman \& Quera, 1995; Haccou \& Meelis, 1992). Nevertheless, the statistical analysis of these sequences requires a huge data-collecting effort that is, of necessity, even greater when so many animal species have to be observed and compared, a required step in any evolutionary study. Magnusson (2000) has presented a software program called Theme that detects nested temporal patterns ( $\mathrm{T}$ patterns); these are complex, syntactical relationships between distinct acts in a time series. T patterns are based on the concept of critical intervals - that is, a minimum real-time window in which the acts that constitute a $\mathrm{T}$ pattern occur in an ordered sequence. $T$ patterns are certainly present in many related species, so this specific kind of temporal pattern could be informative in evolutionary analysis. Nevertheless, $\mathrm{T}$ patterns will only be detected in a group of distinct animal species if all these species show a similar time window for the performance of the same $\mathrm{T}$ pattern. This is not always the case. It is well known 
that evolution can lead to changes in morphometric relations (for the relative sizes of intraorganismal structures see Gould, 1966, 2002), and these changes can lead to corresponding changes in the temporal structure of the movements. Evolutionary changes in the relative sizes of distinct body appendages can result in these same appendages causing changes in the overall temporal structure of the movements. This means that larger animals take longer to display a behavioral sequence than do smaller animals. Thus, the use of T patterns in evolutionary analyses should be sparing, as long as temporal patterns are allometry dependent, so that the use of such characters could lead to grouping together taxa of similar size, instead of grouping together phylogenetically related taxa.

We can eliminate this problem if we deal only with the sequential order of behavioral events (i.e., without taking their onset/offset times into account). Also, if we are to study simultaneously many distinct animal species, for each analysed species we should investigate solutions that do not result in huge data-collecting efforts. As a step in this direction, we are introducing EthoSeq, a program designed to extract probabilistic behavioral sequences, or tree-generated sequences (TGSs), from observational data. With this program, the behavioral data for many species can be compared. EthoSeq prepares a TGS-species matrix that summarizes the information concerning the presence or absence of each TGS in each animal species being studied, a basic input to any cladistic analysis. To demonstrate the program, we analyzed sequences of facial grooming in six felid species, building a phylogeny based on behavioral information.

\section{General Program Structure}

EthoSeq performs stepwise transformation of raw sequential data. Observational sessions (sequences of behavioral acts) are transformed in a first-order transition matrix, where rows represent the precedent act and columns the subsequent act in the sequence. EthoSeq can import either single- or multiple-session observational files; alternatively, it can read a transition matrix directly. The second step is the probabilistic analysis of the behavioral sequences, wherein the program builds on the most probable transitions in forward and backward modes, building directed trees (DiTree), hierarchical diagrams summarizing the information about the sequences of acts (see "Building Behavioral Transition Matrices" and "DiTree Analysis," below). The next step involves the transformation of DiTrees into TGSs, and computing the observed and expected frequencies (according to a first-order transition model) of each TGS based on the raw data (see "Building TGS-Species Matrices," below). At each step, the program can export the partial results to other software packages such as Microsoft Excel (.xls) and Microsoft Word (.doc) files. The program runs under multiple optional screen resolutions.

\section{Building Behavioral Transition Matrices}

EthoSeq reads either single (.odf) or multiple observation files (.mdf) directly from the Observer or Observer
Video-Pro package (Noldus, Trienes, Hendriksen, Jansen, \& Jansen, 2000). It also accepts text files for sequential data, such as those generated by EthoLog (Ottoni, 2000), or from any other source, as long as certain file parameters are respected (example files are provided with the program, available at www.assis.unesp.br/cats/ethoseq.htm). Alternatively, it can import transition matrices built on Excel (.xls) or ASCII (.mat) formats (again, example files are provided). While reading these files, the program can rename, ignore, or fuse user-specified behavioral acts, and it can save this transformed behavioral sequence file for further analysis. A behavioral act can be ignored in "continuous" or "noncontinuous" modes. In the "continuous" mode, the program simply deletes the selected act from the observational file; thus, in the sequence $\mathrm{AABCDBE}$ (where each character is an act), if the act $B$ were ignored in the continuous mode, the new sequence would be AACDE, and formerly nonexistent transitions ( $\mathrm{AC}$ and $\mathrm{DE}$ ) would then occur. Following the same example, the new sequence in the "noncontinuous" mode is $\mathrm{AA}^{*} \mathrm{CD}^{*} \mathrm{E}$, where * stands for an observational discontinuity. In this case, the program does not find any previously nonexistent transition; that is, the transitions $\mathrm{AC}$ and $\mathrm{DE}$ are not present.

The transition matrix can be viewed as a frequency matrix or as a relative transition frequency matrix, and both can be exported to an Excel format file. An iterative chi-square test (see Brown, 1974) with a user-specified significance level can be performed in order to highlight above- and below-chance transitions. In a separate window, the program lists the detected significant transitions and shows the chi square and its probability for each of the steps of the iterative chi-square algorithm. Brown's iterative procedure is a winnowing technique that detects which residuals from the transition frequency matrix are independent and account for the significant association of rows and columns in the matrix. According to Brown, this procedure is preferable to the use of adjusted standardized residuals (see Haberman, 1973), because in the latter method "extreme cells can bias the expected values sufficiently to make it difficult to draw inferences about other than the most extreme cells." Brown's procedure deals with structural zeros with an iterative fitting algorithm that is a derivation of Goodman's (1968) maximum-likelihood estimates of expected values, one that is generalized for more than one missing cell (for details, see Brown, 1974, p. 406 and p. 412).

The significant cells detected by the iterative chi-square test are a useful means by which to describe behavior, inasmuch as they can be selected to build ethograms (flow charts showing the transitions between acts), a usual practice among behavioral researchers (see, e.g., Hazlett, 1977).

In order to proceed to the analysis of behavioral sequences, the main diagonal must be cleared (this is a requirement of the DiTree method; see below). One can choose to keep only the significant cells (detected by the iterative chi square) in order to proceed to the analysis of behavioral sequences, but this is not recommended for phylogenetic analyses: EthoSeq uncovers long behavioral sequences, and it is not necessary for all the first-order 
transitions to be significant in a longer, higher order sequence. If we use only the significant first-order transitions to build the longer behavioral sequences, we will unnecessarily reduce the search area of EthoSeq's algorithm. Alternatively, if we use all the first-order transitions (and not only the significant ones) we recover a large number of TGSs; in the example detailed below, EthoSeq recovers 1,386 distinct TGSs from felid facial grooming behavior. Although this large number of TGSs may not exhaust the grooming repertoire of felids, we are confident that it includes a fairly representative sample of their whole grooming repertoire.
After clearing the main diagonal, the user can choose among alternative methods of probabilistic behavioral sequence extraction (see "Building TGS-Species Matrices," below).

\section{DiTree Analysis}

DiTree analysis is a tree-search procedure based on graph theory that produces a DiTree graphical representation. Each DiTree (see Figure 1) is a hierarchical diagram that has the following characteristics: (1) each act is represented only once; (2) for $N$ acts, the number of represented transitions is $(N-1)$, at most; and (3) the represented transitions

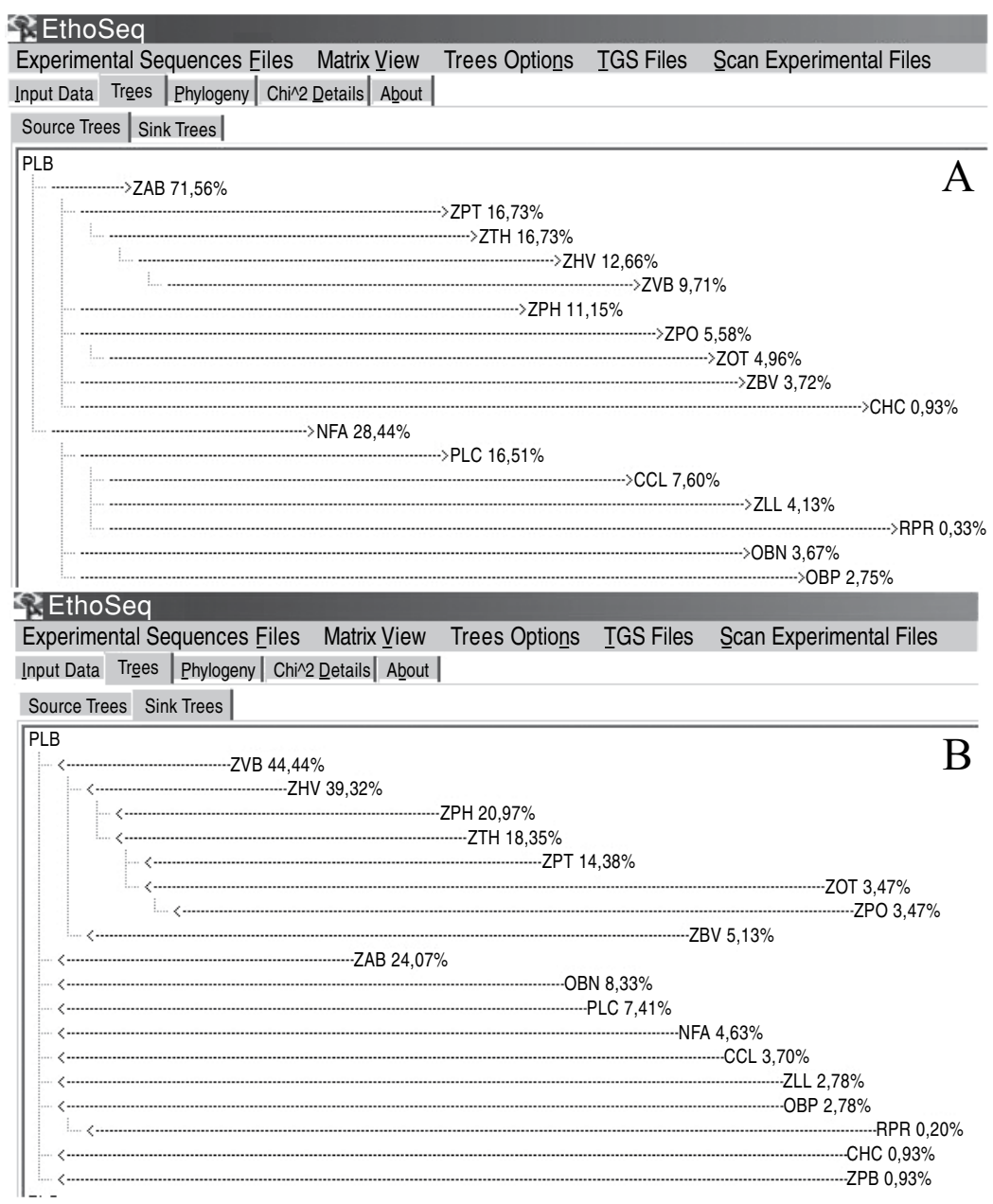

Figure 1. Partial view of EthoSeq's screenshots showing DiTrees with the act PLB as root (see the Appendix for the mnemonics and for the definitions of the acts). The trees represented are the result of the analysis of grooming sequences in cats. (A) Source Trees: PLB precedes all the other acts. The numbers at the right of the acts are the probabilities of each path in the DiTree. For example, the path originating in PLB and ending in ZVB (PLB, ZAB, ZPT, ZTH, ZHV, ZVB) has a 9.71\%, and the path (PLB, ZAB, ZPO) has a $5.58 \%$ probability of occurrence in the observational data. (B) Sink Trees: PLB follows all the other acts. Again, numbers are path probabilities. The lengths of tree branches are inversely proportional to the path probabilities. Note that the program shows the probabilities of the maximal paths (or maximal ares) and also of the partial ares. Thus, the probability of the maximal are $(\mathrm{ZBV}, \mathrm{ZVB}, \mathrm{PLB})$ is $5.13 \%$ and that of its partial arc (ZVB, PLB) is $44.44 \%$, in this data set. 
are those that maximize path probabilities (see below). Like other graphical analyses (e.g., multidimensional scaling analysis, correspondence analysis, cluster analysis), DiTree diagrams should be inspected visually.

DiTree analysis uses a transition matrix where the main diagonal cells are set to structural zeros (see Hooff, 1982; Slater, 1973). The frequency of the cells is replaced by the conditional probability of the column act, given the row act.

The method relies on the enumeration of the most probable elementary path between two given behavioral acts. A first-order transition is represented by an ordered duplet of acts and a path by an ordered arrangement of duplets in which the second act of a duplet is the first act of the next duplet. For example, $\{(\mathrm{A}, \mathrm{B}),(\mathrm{B}, \mathrm{C}),(\mathrm{C}, \mathrm{D})\}$ and $\{(\mathrm{A}, \mathrm{B}),(\mathrm{B}, \mathrm{A}),(\mathrm{A}, \mathrm{D})\}$ are different paths from $\mathrm{A}$ to D. A more economical representation can be obtained by eliminating the redundant information of the common act between adjacent duplets, so (A, B, C, D) is the resulting representation of the first path given above. This is an elementary path - that is, a path that traverses an act only once. Only elementary paths are used in DiTree analysis. The detection of long elementary paths, for example, in the third-order sequence (A, B, C, D), does not mean that there is a significant third-order pattern present in the data.

When the cells of a transition matrix are converted to conditional probabilities so that $c(i, j)$ is the conditional probability of act $j$, given a precedent act $i$ - that is, $c(i, j)=p(j / i)$, and $p(r)$ is the (unconditional) probability of act $r$ - then the probability of traversing the path $(r$, $\ldots, l)$ is

$$
P(r, \ldots, l)=p(r) \prod_{(i, j) \in(r, \ldots, l)} c(i, j) .
$$

We can enumerate the most probable paths from one selected act to all the other acts of the transition matrix (the DiTree source solution); or, alternatively, we can enumerate the most probable paths from every other act to the selected one (the DiTree sink solution). Depending on the probabilistic structure of the transition matrix, a given source act may or may not reach all the other acts of the transition matrix. By the same token, a given sink act may or may not be reached by all other acts.

The most probable DiTree is the one that meets the following conditions:

$$
\begin{aligned}
& P(r, \ldots, j) \geq P(r, \ldots, i) c(i, j), \text { if } r \text { is a source; }(2 \mathrm{~A}) \\
& P(i, \ldots, r) \geq P(j, \ldots, r) c(i, j) p(i) / p(j), \text { if } r \text { is a sink, }
\end{aligned}
$$

for every $(i, j)$ of A, $i \neq j$ (the proofs follow similar steps to those employed by Busacker \& Saaty, 1965).

Essentially, the algorithm for DiTree source solution, partially adapted from those utilized by Busacker and Saaty (1965) for the search of the shortest distance DiTree, performs as follows:

\section{INITIALIZATION}

(A) Construct the transition matrix from the behavior sequence (rows, precedent acts; columns, subsequent acts).
(B) Construct the conditional probability matrix.

(C) The resulting matrix is a probabilistic graph $\mathrm{G}=$ (V,A), for the set of acts $\mathrm{V}$ and the set of conditional probabilities A.

(D) Construct any probabilistic DiTree $\mathrm{T}=\left(\mathrm{V}, \mathrm{A}^{*}\right)$, for $\mathrm{A}^{*}$ a subset of A, rooted at a specified source $r$; by using Equation 1, find the probability of all the paths of T that initiate at $r$.

\section{STEPS}

(1) If the paths of $\mathrm{T}$ obey Equation $2 \mathrm{~A}$ for every arc $(i, j)$ of A, $i \neq j$, then sтоP: $\mathrm{T}$ is the required DiTree rooted at the source $r$ of the graph $\mathrm{G}=(\mathrm{V}, \mathrm{A})$.

(2) Or else modify T as follows:

(a) Select any arc $(i, j)$ of A that does not satisfy Equation 2A.

(b) Disconnect $\mathrm{T}$ by deleting the arc of $\mathrm{T}$ whose terminal act is $j$.

(c) Reconnect $\mathrm{T}$ by adding the $\operatorname{arc}(i, j)$.

(d) Recalculate the probability of the paths of $\mathrm{T}$ that were modified at this step.

(3) Go to Step 1.

It is also easy to find a DiTree converging to a sink, as follows.

\section{INITIALIZATION}

(A), (B), (C), as above.

(D) Construct any probabilistic directed tree $\mathrm{T}=$ (V,A*), for $\mathrm{A}^{*}$ a subset of A, converging to a specified sink $r$; by using Equation 1, find the probability of all the paths of T that terminate at $r$.

STEPS

(1) If the paths of $\mathrm{T}$ obey Equation 2B for every arc $(i, j)$ of $\mathrm{A}, i \neq j$, then STOP: $\mathrm{T}$ is the required DiTree converging to the sink $r$ of the graph $\mathrm{G}=(\mathrm{V}, \mathrm{A})$.

(2) Or modify $\mathrm{T}$ as follows:

(a) Select any arc (i,j) of A that does not satisfy Equation 2B.

(b) Disconnect $\mathrm{T}$ by deleting the $\operatorname{arc}$ of $\mathrm{T}$ whose initial act is $\mathrm{i}$.

(c) Reconnect $\mathrm{T}$ by adding the arc $(\mathrm{i}, \mathrm{j})$.

(d) Recalculate the probability of the paths of $\mathrm{T}$ that were modified at this step.

(3) Go to Step 1.

\section{Building TGS-Species Matrices}

As a result of the DiTree searching procedure, EthoSeq produces $N$ sink and $N$ source trees (where $N$ is the number of behavioral acts included in the analysis). The program can display either the frequency or the probability of occurrence of the arcs in each DiTree; they are shown in a special window for inspection and printing purposes (they also can be saved as text files).

At this step, the program breaks each DiTree down into its maximal arcs (the ones beginning on a root and 
ending on the last leaf; see Figure 1). These directional maximal arcs are then fused two by two, whenever the last (or first) act of one arc is also the last (or first) act of any other arc (keeping track of the directionality of each arc). This fusion procedure is optional and user-specified. This procedure is important because it allows the detection of repetitive behavioral sequences; that is, sequences where the same act appears more than once (see Alberts, 1996).

The program then searches for these fused arcs (or fragments thereof) on the original observational data files (Alberts, 1996). This is done by means of the following disassembling algorithm: (1) Scan the original data files for the sequence; (2) proceed unless the sequence is found, in which case, stop and save it; (3) eliminate the last act from the sequence; and (4) go to Step 1.

This algorithm is then performed again from the beginning, but now with the "last act" (Step 3) substituted for the "first act" (Step 1). In each observational session, the saved sequences (TGSs) and their frequencies are counted. The detection of long TGSs - for example, the fourthorder sequence (ABCDE) - does not mean that there is a significant fourth-order pattern present in the data. The DiTree search algorithm is a probabilistic method that is not intended to test statistically the significance of highorder sequences. If we were to test these long sequences in each of the animal species included in the evolutionary analysis, we would need a sampling effort beyond the scope of most comparative studies. The method presented here allows a reduction of this sampling effort, rendering feasible evolutionary studies of behavioral sequences.

Also, an expected frequency is obtained for each TGS, based on a first-order transition model. If $\mathrm{ABC}$ is the behavioral sequence, and $N$ is the matrix total, the expected frequency is $p(\mathrm{~A}) \times p(\mathrm{~B} / \mathrm{A}) \times p(\mathrm{C} / \mathrm{B}) \times N$, where $p(\mathrm{~A})$ is the unconditional probability of $\mathrm{A}$ and $p(i / j)$ is the conditional probability of any behavior $i$, given behavior $j$. As a result, the program displays a matrix with TGSs as rows and its frequencies on the observational sessions (raw data). TGSs can be used as phylogenetic characters.

\section{Determining Phylogenetic Characters (Behavioral Sequences)}

Alberts (1996) first proposed the use of behavioral sequences as phylogenetic characters, and the algorithm presented here is an improvement on this original proposal. For example, in the original proposal, if the sequence $\mathrm{ABCD}$, where each letter stands for one act, were detected, its subsets (ABC and $\mathrm{AB}$ ) would also be scored as present in the final output; this procedure might result in a loss of independence between the detected sequences, so we devised the new algorithm, presented above, to mitigate this problem.

Whereas Alberts (1996) concentrated on the DiTrees of one particular behavioral act, EthoSeq uses the diagrams of all observed behavioral categories. Also, unlike Alberts, who combined only source-destination DiTrees in this particular order, EthoSeq combines also destination-source, destination-destination, and sourcesource DiTrees for each behavior. In doing so, EthoSeq fuses a maximal arc to any other possible maximal arc. This way, EthoSeq retrieves a much larger number of TGSs than did the original methodology. This large number of TGSs gives us confidence that most of the hidden patterns of behavioral sequences present in the raw data, even those of order greater than one, can be recovered by the EthoSeq algorithm.

The sequences obtained from all the species are merged into a single file (.tgs), and the program looks for the occurrence of these sequences in the original data (observational sessions) for all the species, building a matrix with sequences as rows and species as columns. This output is a character matrix, to be used in maximum-parsimony cladistic analysis. It can be exported to Excel format, where it can be modified to suit the specifics of the input files of programs such as PAUP* (see Swofford, 2002), among others.

\section{Phylogenetic Characters on Felid Grooming: An Example}

The analysis of behavioral sequences detected through the graph methodology herein presented was already employed in a series of studies on spider foraging, in order to detect behavioral differences between experimental treatments (see Japyassú \& Viera, 2002), to estimate repertoire amplitude (see Caires \& Japyassú, 2003; Garcia \& Japyassú, 2005; Japyassú \& Jotta, 2005), or to compare repertoire plasticity among different species (see Japyassú, Alberts, Izar, \& Sato, 2003). In order to make clearer the usefulness of EthoSeq, not only for the analysis of behavioral sequences but also for the phylogenetic analysis of behavior, we will discuss an example applied to grooming sequences in seven felid species (see Alberts, 1996).

Grooming is a self-directed, stereotypical behavior (see Berridge, 1990). The pattern is usually quite fixed; the choreography of the movements varies very little, and all the individuals of the same species display this behavior (see Galera, Toyoda, \& Dobrianskyj, 1983). In addition, it seems to be a type of behavior that is neither learned nor even altered by learning (see Annable \& Wearden, 1979; Fentress, 1973; Konorski, 1967; Shettleworth, 1972). Studying grooming behavior therefore seems to be a good means of obtaining stereotypical behavioral sequences.

The species used in the research (the ingroup) were the adult domestic cat (Felis catus); the Bengal cat (Felis bengalensis); the caracal lynx (Felis caracal); the serval (Felis serval); Geoffroy's cat (Felis geoffroyi); and the Asiatic golden cat (Felis temminckii). The felid nomenclature used in this study follows Gittleman (1991). We used 24 facial grooming acts, which are listed and described in the Appendix.

Any characteristic to be used in an evolutionary study must be homologous among species. Following Greene (1994), we considered the topological correspondence between acts (i.e., their position in a TGS) and the temporal direction of the paths as evidence of homology.

Some of the TGSs - for example, the sequence [ZHV ZVB PLB ZAB ZPO ZOT ZTH ZHV ZVB PLB]occurred in all the species (see the Appendix for the mnemonics and the description of the acts). Others, such as 
[PLC ZPO] occurred in only one of the species (the caracal lynx). Sequences such as these, which occur in only one or in all of the studied taxa, provide no information concerning the grouping of the species. They are phylogenetically uninformative and were not considered in this analysis. The analysis of the facial grooming with EthoSeq generated 608 informative TGSs, which were used as characters in the subsequent phylogenetic analysis.

\section{Cladistic Analysis of Felid Grooming}

The determination of the plesiomorphic state of the characters (in evolutionary terms, the characters' ancestral state) was based on the comparison to viverrids and hyenids, the closest groups to felids (Forey et al., 1992). None of these animals presented facial grooming, and therefore facial grooming was considered an apomorphy (an evolutionary novelty) of Felidae. Thus, it was inferred that the ancestors of Felidae were the first to possess at least part of this behavioral structure.

We analyzed the behavioral data using the principles and methodologies described by Hennig (1966), as implemented in the program PAUP* 4.0 (see Swofford, 2002). As a result of the analysis of these 608 behavioral characteristics, there was only one cladogram (Figure 2). This is not a usual result. A recent study involving the phylogeny of felids, using a combination of cranial and corporal morphology (using only 59 characters) resulted in 409 cladograms. Our result suggests that facial grooming evolved in a more harmonic way than did other characteristics of felids; we may, therefore, conclude that the use of behavioral sequences is helpful for phylogenetic reconstruction and should be expanded.

\section{Concluding Remarks}

EthoSeq has been used in the phylogenetic analysis of the grooming behavior in felids (Alberts, 1996) and birds (see Quadros, 2002). In both studies the use of EthoSeq resulted in a large number of TGSs, which together yielded single phylogenetic trees with high consistency and retention indexes. Preliminary analyses of spider foraging behavior (Japyassú et al., 2003) also yielded a large number of TGSs, one single tree, and high consistency and retention indexes. Together, these analyses show that behavioral sequences are useful for detecting evolutionary patterns. We hope that the automation of the method for

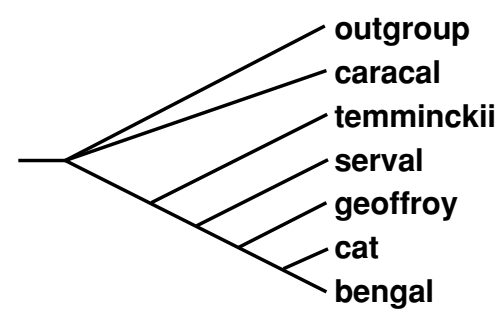

Figure 2. The single cladogram resulting from the parsimony analysis of 608 informative TGSs. In total, 778 uninformative TGSs were not included in this analysis. Most TGSs are not homoplasies (consistency index, $\mathrm{CI}=\mathbf{5 1}$ ). Length of the cladogram = 1,198. Retention index $=29$. the extraction of behavioral sequences with the EthoSeq program will encourage other researchers of animal behavior to test the usefulness of other behavioral data for cladistic analysis.

EthoSeq is not only useful in cladistic analysis; it is also an important tool in the detailed structure analysis of behavior sequential structure and in the analysis of social relationships. The TGSs obtained by means of EthoSeq can be used to statistically compare groups of animals submitted to different experimental treatments (see Japyassú \& Viera, 2002; Oliveira, 2002). Also, matrices representing the frequency of a behavioral act between pairs of individuals in a social group (instead of the frequency of a transition between distinct acts in a behavioral sequence of one or more individuals) can be usefully analyzed with EthoSeq. The DiTrees can thus be interpreted as a summary only of dyadic relationships between members within the group: in this sense, EthoSeq is also helpful in the study of social phenomena.

\section{REFERENCES}

Alberts, C. C. (1996). O comportamento de autolimpeza do gato doméstico (Felis catus) e uma proposta para usá-lo como caractere filogenético. Unpublished doctoral thesis, University of São Paulo.

Annable, A., \& Wearden, J. H. (1979). Grooming movements as operants in the rat. Journal of the Experimental Analysis of Behavior, 32, 297-304.

Atz, J. W. (1970). The application of the idea of homology to behavior. In L. R. Aronson, E. Tobach, D. S. Lehrman, \& J. S. Rosenblatt (Eds.), Development and evolution of behavior: Essays in honor of T. C. Schneirla (pp. 53-74). San Francisco: Freeman.

BaKeman, R., \& GotTMan, J. M. (1997). Observing interaction: An introduction to sequential analysis. Cambridge: Cambridge University Press.

BaKeman, R., \& Quera, V. (1995). Analyzing interaction: Sequential analysis with SDIS and GSEQ. New York: Cambridge University Press.

BerRIDGE, K. C. (1990). Comparative fine structure of action: Rules of form and sequence in the grooming patterns of six rodent species. Behaviour, 113, 21-56.

Brooks, D. R., \& McLennan, D. A. (1991). Phylogeny, ecology, and behavior: A research program in comparative biology. Chicago: University of Chicago Press.

Brown, M. B. (1974). Identification of the sources of significance in two-way contingency tables. Applied Statistics, 23, 405-413.

BusaCKer, R. G., \& SAATY, T. L. (1965). Finite graphs and networks. New York: McGraw-Hill.

Caires, R. A., \& Japyassú, H. F. (2003). Predatory plasticity in a new spider species: An expression of web architecture? Revista de Etologia, 5, 149-150.

De QueIroz, A., \& Wimberger, P. H. (1993). The usefulness of behavior for phylogeny estimation: Levels of homoplasy in behavioral and morphological characters. Evolution, 47, 46-60.

Fentress, J. C. (1973). Development of grooming in mice with amputated forelimbs. Science, 179, 704-705.

Forey, P. L., Humphries, C. J., Kitching, I. L., Scotland, R. W., SieBERT, D. J., \& Williams, D. M. (1992). Cladistics: A practical course in systematics. Oxford: Oxford University Press, Clarendon Press.

Galera, C. A., Toyoda, C. Y., \& Dobrianskyu, L. N. (1983). Descrição etológica dos comportamentos de ratos albinos. Monografia em Etologia, Departamento de Psicologia Experimental, Instituto de Psicologia da Universidade de São Paulo.

Garcia, C. R. M., \& Japyassú, H. F. (2005). Stereotypy and plasticity in the predatory sequence of Theridion evexum, Keyserling 1884 (Araneae: Theridiidae). Biota Neotropica, 5(1A). Available at www .biotaneotropica.org.br/v5n1a/en/abstract?article + BN001051a2005.

Gittleman, J. L. (Ed.) (1991). Carnivore behavior, ecology and evolution. Ithaca: Cornell University Press.

Goodman, L. A. (1968). The analysis of cross-classified data: Inde- 
pendence, quasi-independence, and interactions in contingency tables with or without missing entries. Journal of the American Statistical Association, 63, 1091-1131.

Gould, S. J. (1966). Allometry and size in ontogeny and phylogeny. Biological Reviews, 41, 587-640.

Gould, S. J. (2002). The structure of evolutionary theory. Cambridge, MA: Harvard University Press, Belknap Press.

Greene, H. W. (1994). Homology and behavioral repertoires. In B. K. Hall (Ed.), Homology: The hierarchical basis of comparative biology (pp. 369-391). San Diego: Academic Press.

Haberman, S. J. (1973). The analysis of residuals in cross-classified tables. Biometrics, 29, 205-220.

Haccou, P., \& Meelis, E. (1992). Statistical analysis of behavioral data: An approach based on time-structured models. Oxford: Oxford University Press.

HaZletT, B. A. (Ed.) (1977). Quantitative methods in the study of animal behavior. New York: Academic Press.

Hennig, W. (1966). Phylogenetic systematics. Chicago: University of Illinois Press.

Hooff, J. A. R. A. M. van (1982). Categories and sequences of behavior: Methods of description and analysis. In K. R. Scherer \& P. Ekman (Eds.), Handbook of methods in nonverbal behavior research (pp. 362-439). Cambridge: Cambridge University Press.

Japyassú, H. F., Alberts, C. C., Izar, P., \& Sato, T. (2003). Sinal filogenético em seqüências comportamentais longas: A plasticidade introduz ruído na análise? In IV Encontro de Aracnólogos do Cone Sul, 4, 44-45.

JAPYASSÚ, H. F., \& JotTA, E. G. (2005). Foraging in Achaearanea cinnabarina Levi 1963 (Araneae, Theridiidae) and evolution of hunting in spiders with irregular webs. Biota Neotropica, 5(1A). Available at www.biotaneotropica.org.br/v5n1a/en/abstract?article + BN0030 $51 \mathrm{a} 2005$.

JAPYASSÚ, H. F., \& VIERA, C. (2002). Predatory plasticity in Nephilengys cruentata (Araneae, Tetragnathidae): Relevance for phylogeny reconstruction. Behaviour, 139, 529-544.

KONORSKI, J. (1967). Integrative activity of the brain. Chicago: Univesity of Chicago Press.

Magnusson, M. S. (2000). Discovering hidden time patterns in behavior: T-patterns and their detection. Behavior Research Methods, Instruments, \& Computers, 32, 93-110.
Martins, E. P. (1996). Phylogenies and the comparative method in animal behavior. New York: Oxford University Press.

McLennan, D. A., Brooks, D. R., \& McPhail, J. D. (1988). The benefits of communication between comparative ethology and phylogenetic systematics: A case study using gasterosteid fishes. Canadian Journal of Zoology, 66, 2177-2190.

Noldus, L. P. J. J., Trienes, R. J. H., Hendriksen, A. H. M., Jansen, H., \& JANSEN, R. G. (2000). The Observer Video-Pro: New software for the collection, management, and presentation of time-structured data from videotapes and digital media files. Behavior Research Methods, Instruments, \& Computers, 32, 197-206.

Odling-Smee, F. J., Laland, K. N., \& Feldman, M. W. (2003). Niche construction: The neglected process in evolution. Princeton: Princeton University Press.

Oliveira, A. P. F. (2002). Comportamento social de machos e fêmeas castrados do gato doméstico (Felis catus) em confinamento. Unpublished master's thesis, University of São Paulo.

Ottoni, E. B. (2000). EthoLog 2.2: A tool for the transcription and timing of behavior observation sessions. Behavior Research Methods, Instruments, \& Computers, 32, 446-449.

Paterson, A. M., Wallis, G. P., \& Gray, R. D. (1995). Penguins, petrels, and parsimony: Does cladistic analysis of behavior reflect seabird phylogeny? Evolution, 49, 974-989.

Prum, R. O. (1994). Phylogenetic analysis of the evolution of alternative social behavior in the manakins (Aves: Pipridae). Evolution, 48, $1657-1675$

Quadros, A. H. (2002). Filogenia da família Cathartidae (Aves) baseada em comportamento de autolimpeza. Unpublished master's thesis, University of São Paulo.

SHETTLEWORTH, S. F. (1972). Constraints on learning. In D. S. Lehrman, R. A. Hinde, \& E. Shaw (Eds.), Advances in the study of behavior (pp. 4.1-4.68). New York: Academic Press.

Slater, P. J. B. (1973). Describing sequences of behavior. In P. P. G. Bateson \& P. H. Klopfer (Eds.), Perspectives in ethology (pp. 131153). New York: Plenum.

SLIKAS, B. (1998). Recognizing and testing homology of courtship displays in storks (Aves: Ciconiiformes: Ciconiidae). Evolution, 52, 884-893.

Swofford, D. L. (2002). PAUP*: Phylogenetic Analysis Using Parsimony (*and other methods) (Version 4) [Computer software]. Sunderland, MA: Sinauer. 
APPENDIX

The mnemonic codes are as follows:

PLB: Downward protraction of the tongue. The animal opens its mouth, protracts its tongue upward to about $1 / 3$ of the tongue's maximum extension, then curves it downward.

PLC: Upward protraction of the tongue. The animal opens its mouth, protracts its tongue upward to about $1 / 3$ of the tongue's maximum extension, then curves it upward and protracts it to about $1 / 2$ of its maximum extension.

CCL: Cleaning the central septum. Departing from PLC, the animal protracts its tongue to the tip of its nose and touches the surface of its nose before retracting its tongue.

ZLL: Upper lip. Departing from PLC, the animal protracts its tongue as far as the tip of the nose; then, opening its mouth wide, it moves its tongue along the upper lip to the corner of the mouth, when it retracts its tongue and closes its mouth.

ZAB: Forearm. After PLB, with one paw raised and turned inward, the animal lowers its head toward its chest, licks itself at the base of the forearm, then, slowly raising its head while moving its paw backward, it licks itself along the forearm and retracts its tongue.

ZPA: Palmal. With its paw raised and turned inward toward its face, the animal, departing from PLB, lowers its head toward its chest, licks the closest part of the pad of its paw, and moves its head away from its chest before retracting its tongue.

ZPV: Paw to whiskers. Departing from ZAB, without touching its face with its paw, but moving its head and arm, it grooms the upper lip and whiskers.

ZPH: Paw to eyes. Departing from ZAB, without touching its face with its paw but moving its head and arm, the animal grooms its whiskers, its upper lip, and around and above its eyes.

ZPT: Paw to forehead. Departing from ZAB, not touching its face with its paw but moving its head and arm, the animal grooms its upper lip, whiskers, eye area and forehead until its paw reaches the base of its ear, in front.

ZPO: Paw to ear. Departing from ZAB, without touching its face with its paw but moving its head and arm, the animal grooms its upper lip, whiskers, eye area, forehead and ear, finishing with its paw behind its ear.

ZVB: Whiskers to mouth. Departing from ZPV, together with movements of the arm and head, the paw slides until the forearm is in the right position for the beginning of ZAB.

ZHV: Eye to whiskers. Departing from ZPH, together with movements of the arm and head, the paw slides until the forearm is above the whiskers.

ZHV: Forehead to eye. Departing from ZPT, together with movements of the arm and head, the paw slides until the forearm is above the eyes.

ZOT: Ear to forehead. Departing from ZPO, together with movements of the arm and head, the paw slides until the forearm is above the base of the ear.

NFA: Non-facial cleaning. Departing from PLB, licking any part of the body except the paw pads or forearm; with head and body movements, the animal licks its fur.

OBP: Static observation. Immobile, the eyes fixed on something.

OBN: Non-static observation. The same as OBP, but with some body movement, mainly of the head.

COM: Eating. The animal approaches food, nibbles and licks it, and/or ingests it.

ZPB: Paw toward mouth. When lying, sitting, or standing, the animal raises a forepaw toward its mouth.

CHC: Shaking the head. When lying, sitting, or standing, the animal closes its eyes and turns its head rapidly back and forth two or three times.

RPR: Posture readjustment. When lying, sitting, or standing, the animal moves slightly to change position. AND: Walking. When at rest, the animal moves its paws in a coordinated fashion in order to move slightly.

(Manuscript received December 23, 2003;

revision accepted for publication June 24, 2005.) 